\title{
Serum neutrophil gelatinase-associated lipocalin as a marker of kidney function in pregnancy - useful or doubtful?
}

Jacek S. Małyszko', Leszek Rams², Lena Drozdowska-Rams³, Jolanta Małyszko

${ }^{1}$ Department of Nephrology and Transplantology, Medical University, Bialystok, Poland ${ }^{2}$ Gynaecology and Obstetrics Unit, Regional Hospital, Ostroda, Poland

3Haematology Unit, Regional Hospital, Olsztyn, Poland

Submitted: 19 December 2009

Accepted: 27 April 2010

Arch Med Sci 2010; 6, 5: 744-747

DOI: 10.5114/aoms.2010.17090

Copyright (c) 2010 Termedia \& Banach

\author{
Corresponding author: \\ Jolanta Małyszko MD, PhD \\ Department of Nephrology \\ and Transplantology \\ Medical University \\ Zurawia 14 Str. \\ 15-540 Bialystok, Poland \\ Phone: +48 857409464 \\ Fax: +48 857412391 \\ E-mail: \\ jolmal@poczta.onet.pl
}

\begin{abstract}
Introduction: The aim of the study was to assess whether neutrophil gelatinaseassociated lipocalin (NGAL) and cystatin $\mathrm{C}$ could reflect kidney function in pregnant healthy women.

Material and methods: The studies were performed on 130 healthy pregnant women ( $n=63,3^{\text {rd }}$ trimester; $n=21,2^{\text {nd }}$ trimester; $n=46,1^{\text {st }}$ trimester $)$ and 30 healthy female volunteers. Serum NGAL, cystatin C, IL-6, and hs-CRP were assayed using commercially available kits.

Results: Serum cystatin C rose steadily during the pregnancy, whereas NGAL rose in the $2^{\text {nd }}$ trimester, then decreased in the $3^{\text {rd }}$ trimester. In univariate analysis, NGAL correlated with serum cystatin C, number of pregnancies, white blood cell count, total iron-binding capacity (TIBC), ferritin, and IL-6, and tended to correlate with eGFR. In multiple regression analysis the only predictor of serum NGAL was cystatin C.

Conclusions: Serum NGAL in pregnancy might reflect subclinical inflammation rather than kidney function. It seems that NGAL, similarly to cystatin C, is not useful to monitor renal function in pregnancy.
\end{abstract}

Key words: NGAL, cystatin C, pregnancy, cytokines, IL-6, eGFR, kidney function, creatinine.

\section{Introduction}

Normal pregnancy is characterized by profound changes in almost every organ system to accommodate the demands of the fetoplacental unit. Normal pregnancy is also characterized by increased renal perfusion, i.e. a rise in the glomerular filtration rate (GFR) and renal blood flow. The increase in GFR can be demonstrated within one month of conception and reaches a peak approximately $40 \%$ to $50 \%$ above baseline levels by the end of the first trimester [1]. Moreover, renal blood flow increases by $80 \%$ above non-pregnant values. The glomerular hyperfiltration results in a normal reduction in the plasma creatinine concentration to about $0.4 \mathrm{mg} / \mathrm{dl}$ to $0.5 \mathrm{mg} / \mathrm{dl}(35 \mathrm{mmol} / \mathrm{l}$ to $44 \mathrm{mmol} / \mathrm{l})$; thus, a "normal" level of $0.8 \mathrm{mg} / \mathrm{dl}(70 \mathrm{mmol} / \mathrm{l})$ during pregnancy represent a mild decline in renal function, possibly from some underlying renal disease. It is well known that serum creatinine is an imperfect marker to measure GFR. There has been interest in exploring other biomarkers 
for estimating renal function. The most promising agent seems to be cystatin C [2]. The value of neutrophil gelatinase-associated lipocalin (NGAL) was highlighted as a novel biomarker of kidney function [3]. Because of its small molecular size $(25 \mathrm{kDa})$ and resistance to degradation, NGAL is readily excreted and detected in urine as cystatin C. Taking all these data into consideration, the aim of the study was to assess whether NGAL could reflect kidney function in pregnant healthy women. We also assessed correlations between NGAL, cystatin C, creatinine and estimated GFR (eGFR) using 3 formulae.

\section{Material and methods}

We assessed kidney function in 130 healthy pregnant women ( $n=46,1^{\text {st }}$ trimester, $n=21$, $2^{\text {nd }}$ trimester and $n=63,3^{\text {rd }}$ trimester) and 30 healthy female volunteers (to establish the normal range for NGAL). The inclusion criteria were: physiological, uncomplicated pregnancy, no inflammation/infection, no prior kidney disease. The exclusion criteria were: complications of pregnancy (imminent abortion, premature delivery, bleeding, cramps requiring drugs/hospitalizations), history of kidney diseases, anaemia, infection, comorbidities (diabetes, hypertension, etc). Since NGAL is affected by kidney function [3] we included only females with normal kidney function (creatinine less than $1.2 \mathrm{mg} / \mathrm{dl}$, eGFR in the normal range of $90-120 \mathrm{ml} / \mathrm{min}$ ). All the subjects were informed about the aim of the study and gave their consent. The study was approved by the local Medical University Ethic Committee. Healthy volunteers were recruited mainly from the medical staff and their friends and families. We assessed kidney function according to the simplified MDRD equation ( $\mathrm{eGFR}=186.3 \times$ serum creatinine $(\mathrm{mg} / \mathrm{dl})^{-1.14} \times$ age $^{-0.203} \times 0.742$ if female $\times 1.21$ if AfroAmerican) and Cockcroft-Gault formula (creatinine clearance $=[140$-age $] \times$ body weight/serum creatinine $\times 72$ if female $\times 0.85$ ) and new CKD-EPI formula [4].

Serum NGAL (ANTIBODYSHOP, Gentofte, Denmark), cystatin C (Dade Behring, Marburg, Germany), IL-6 (R\&D, Abingdon, UK), hs-CRP (American Diagnostica, Greenwich, CT, USA) were assayed using commercially available kits. Complete blood count, serum iron, total iron-binding capacity (TIBC), ferritin, and creatinine were assayed by means of standard laboratory methods in the central laboratory. All tests were performed according to manufacturers' instructions by the same person. ANOVA or Kruskal-Wallis ANOVA was used in statistical analysis.

\section{Results}

All the data are presented in Table I. We observed a statistically significant fall in serum

Table I. Basal clinical and biochemical characteristics of the studied groups

\begin{tabular}{|c|c|c|c|c|}
\hline & $\begin{array}{l}\text { Healthy volunteers } \\
\qquad n=30\end{array}$ & $\begin{array}{c}1^{\text {st }} \text { trimester } \\
n=46\end{array}$ & $\begin{array}{l}2^{\text {nd }} \text { trimester } \\
\quad n=21\end{array}$ & $\begin{array}{c}3^{\text {rd }} \text { trimester } \\
\quad n=63\end{array}$ \\
\hline Age [years] & $29.8 \pm 8.4$ & $26.7 \pm 5.2$ & $26.2 \pm 5.8$ & $26.6 \pm 5.5$ \\
\hline Number of pregnancies & $1.5 \pm 0.9$ & $3.2 \pm 1.8$ & $1.8 \pm 1.6$ & $1.7 \pm 0.9$ \\
\hline $\mathrm{Ht}[\%]$ & $39.87 \pm 2.48$ & $35.37 \pm 3.45^{*}$ & $33.39 \pm 2.19^{\star * *}$ & $33.12 \pm 3.71^{\star \star *}$ \\
\hline $\mathrm{Hb}[\mathrm{g} / \mathrm{dl}]$ & $13.87 \pm 0.94$ & $12.59 \pm 1.38$ & $12.13 \pm 1.19^{*}$ & $11.06 \pm 1.41^{\star * *}$ \\
\hline Erythrocyte count $\left[\times 10^{12} / \mathrm{I}\right]$ & $4.24 \pm 0.29$ & $4.02 \pm 0.36^{\star}$ & $3.75 \pm 0.34^{\star \star \star}$ & $3.69 \pm 0.35^{\star * *}$ \\
\hline Leukocyte count $\left[\times 10^{12} / \mathrm{I}\right]$ & $5.53 \pm 1.61$ & $7.96 \pm 1.88^{*}$ & $10.26 \pm 2.52^{\star \star \star}$ & $9.85 \pm 2.32^{\star \star \star}$ \\
\hline Neutrophil count $\left[\times 10^{12} / I\right]$ & $4.87 \pm 3.87$ & $5.56 \pm 1.79$ & $6.98 \pm 2.14^{\star \star \star}$ & $7.32 \pm 2.38^{\star \star \star}$ \\
\hline Platelet count $\left[\times 10^{9} / \mathrm{I}\right]$ & $241.45 \pm 44.55$ & $239.32 \pm 61.01$ & $240.45 \pm 51.45$ & $210.24 \pm 47.91$ \\
\hline NGAL [ng/ml] & $18.34 \pm 4.65$ & $19.96 \pm 24.16$ & $38.85 \pm 25.08^{*}$ & $24.03 \pm 21.52$ \\
\hline Cystatin C [mg/l] & $0.82 \pm 0.18$ & $0.81 \pm 0.19$ & $0.86 \pm 0.22$ & $1.24 \pm 0.37^{\star *}$ \\
\hline MDRD equation [ml/min] & $99.78 \pm 14.42$ & $116.88 \pm 17.6^{*}$ & $164.68 \pm 54.1^{\star * *}$ & $132.77 \pm 28.43^{* * *}$ \\
\hline Cockcroft-Gault formula [ml/min] & $98.76 \pm 18.76$ & $128.72 \pm 22.98^{\star}$ & $182.75 \pm 56.54^{\star \star \star}$ & $172.05 \pm 39.22^{\star \star \star}$ \\
\hline CKD-EPI formula [ml/min] & $101.03 \pm 13.32$ & $118.68 \pm 11.29^{*}$ & $133.24 \pm 11.78^{\star * *}$ & $123.22 \pm 14.58^{* * *}$ \\
\hline Creatinine $[\mathrm{mg} / \mathrm{dl}]$ & $0.77 \pm 0.14$ & $0.66 \pm 0.09^{*}$ & $0.51 \pm 0.11^{*}$ & $0.61 \pm 0.13^{*}$ \\
\hline hslL 6 [pg/ml] & $2.26 \pm 2.02$ & $5.61 \pm 2.85^{\star \star}$ & $6.95 \pm 3.62^{\star * *}$ & $7.52 \pm 4.16^{\text {***}}$ \\
\hline $\mathrm{hs}-\mathrm{CRP}[\mathrm{mg} / \mathrm{ml}]$ & $1.74 \pm 0.52$ & $2.71 \pm 1.88$ & $4.21 \pm 2.54^{\star \star}$ & $6.19 \pm 3.56^{\star \star *}$ \\
\hline Iron [ [ug/dl] & $110.56 \pm 25.76$ & $97.35 \pm 32.15$ & $92.09 \pm 44.59$ & $87.17 \pm 41.37^{\star}$ \\
\hline $\mathrm{TIBC}[\mu \mathrm{g} / \mathrm{dl}]$ & $328.98 \pm 84.31$ & $359.12 \pm 77.58$ & $323.81 \pm 70.84$ & $514.99 \pm 87.62^{*}$ \\
\hline Ferritin [ng/dl] & $30.22 \pm 17.43$ & $27.63 \pm 19.52$ & $38.31 \pm 34.68$ & $28.66 \pm 27.82$ \\
\hline
\end{tabular}

Values given are means $\pm S D,{ }^{*} p<0.05,{ }^{* *} p<0.01,{ }^{* * *} p<0.001$ vs. control group 


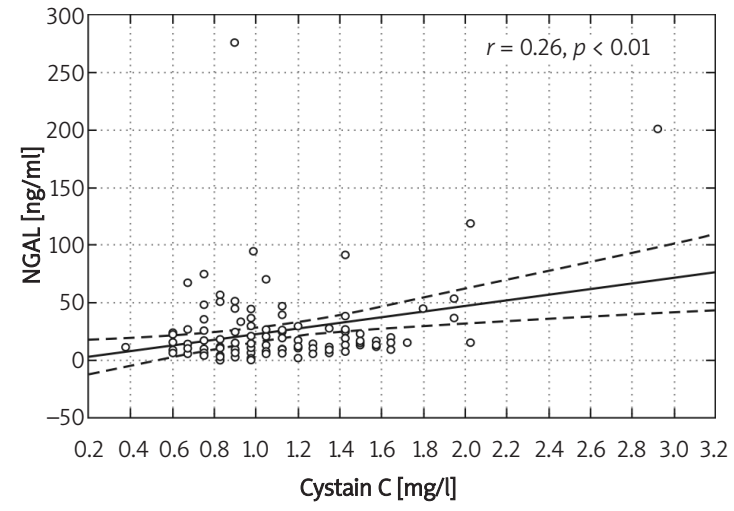

Figure 1. Correlation between NGAL and cystatin C in pregnant females

creatinine in the $2^{\text {nd }}$ trimester together with a rise in eGFR, when compared with the 1st trimester. Serum cystatin $C$ rose steadily during the pregnancy, whereas NGAL rose in the $2^{\text {nd }}$ trimester, then decreased in the $3^{\text {rd }}$ trimester. In pregnant females, eGFR (all formulae) was significantly higher in the $2^{\text {nd }}$ trimester when compared to the $1^{\text {st }}$ and $3^{\text {rd }}$ trimesters. NGAL correlated with serum cystatin C $(r=0.25, p<0.05)$, number of pregnancies $(r=0.25$, $p<0.05)$, white blood cell count $(r=0.29, p<0.01)$, neutrophil count $(r=0.35, p<0.01)$, TIBC $(r=-0.21$, $p<0.05)$, ferritin $(r=0.36, p<0.01)$, and IL-6 $(r=0.23, p<0.05)$, and tended to correlate with eGFR. Serum cystatin C correlated with eGFR by $\operatorname{MDRD}(r=-0.19, p<0.05)$, white blood cell count $(r=0.22, p<0.05)$, neutrophil count $(r=0.33$, $p<0.001)$, TIBC $(r=0.43, p<0.001)$, IL-6 $(r=0.30$, $p<0.01)$, hs-CRP $(r=0.20, p<0.05)$, number of pregnancies $(r=0.45, p<0.001)$, and NGAL $(r=0.25, p<0.05)$ (Figure 1$)$, and tended to correlate with creatinine. In multiple regression analysis the associate of serum NGAL was cystatin $C$ (beta value 0.84, $p=0.008$ ), multiple adjusted $r^{2}=0.70, F=2.99, p<0.034, \mathrm{SE}=5.54$.

In multiple regression analysis, the associates of cystatin C were NGAL (beta value -0.42 , $p=0.00016$ ), neutrophil count (beta value 0.58 , $p=0.02$ ), and IL-6 (beta value 0.34, $p=0.0019$ ), explaining $63 \%$ of the variations of cystatin C concentration $(F=13.15, p<0.000001, \mathrm{SE}=0.23)$.

In healthy females, serum NGAL correlated with age $(r=0.35, p<0.05)$, serum creatinine $(r=0.47$, $p<0.01)$, eGFR $(r=-0.59, p<0.001)$, leukocyte count $(r=0.36, p<0.05)$, and cystatin C $(r=0.44$, $p<0.01)$.

\section{Discussion}

We have shown in our study that in pregnant healthy females, NGAL did not reflect changes in GFR during pregnancy. The only predictor of NGAL concentration was cystatin $C$. The high rate of filtration in pregnancy persists until term [1]. Serum creatinine is an imperfect marker to measure GFR because the total amount of creatinine in plasma water, and therefore the plasma concentration, is dependent on muscle mass, as well as some lesser variables. When any single measurement of plasma creatinine is compared to the whole range of normal values, a marked reduction in renal function ( $40 \%$ to $50 \%$ ) is necessary before a rise in plasma creatinine into the abnormal range is observed. Efforts have been made to measure GFR from a single measurement of creatinine using various formulae to account for dependent variables. However, accuracy has been poor when the creatinine value has been in the normal or near normal range. In recent years, there has been interest in exploring other biomarkers for estimating renal function. Inspection of reports where cystatin C was compared to gold standard markers has resulted in mixed reviews concerning its potential usefulness [5]. In addition, cystatin is affected by hyper- and hypothyroidism, and, as we also observed in our study, has been correlated with markers of inflammation (C-reactive protein) [6]. Although cystatin $C$ appears to be more accurate for the assessment of GFR than serum creatinine in certain populations, whether or not measurement of cystatin C levels will improve patient care is unknown at present.

In contrast to the expected decrease in cystatin C during the first and second trimesters, as observed in the levels of plasma creatinine, the serum levels of cystatin C increased in pregnancy [7]. Cysteineproteases are important in pregnancy for implantation and trophoblast invasion of the placenta. Cystatin C is the strongest extracellular inhibitor of cysteine proteases and was originally cloned from placental cDNA [8]. A study that analysed expression of cystatin at the mRNA and protein level in human placental tissue from normal and pre-eclamptic pregnancies showed that cystatin C was synthesized by the placenta and secreted by trophoblast cells into the fetal and maternal circulation [9]. Cystatin C played a role in placentation, and placental production accounted for the increase in cystatin $C$ in normal pregnancy and the further rise in pre-eclampsia [9]. However, it is doubtful that cystatin $C$ will be useful in monitoring renal function in pregnancy.

In contrast to cystatin C, very little is known about NGAL and the female reproductive tract. NGAL has been found in amniotic fluid, cervical mucus, and coloster [10]. However, the function of NGAL was not revealed in this study. Lavery et al. [11] found that urine NGAL was easily obtained in premature infants and that it correlated significantly with both birth weight and gestational age.

Neutrophil gelatinase-associated lipocalin belongs to the lipocalin family of proteins; NGAL 
was originally isolated from the supernatant of activated human neutrophils, but it is also expressed at a low level in other human tissues including the kidney [12]. Neutrophil gelatinaseassociated lipocalin is synthesized systemically in response to kidney damage followed by glomerular filtration and tubular uptake; it could also be produced locally by injured tubules. In our study with pregnant women, both cystatin $\mathrm{C}$ and NGAL correlated with markers of inflammation better than with eGFR; they did not even show a significant correlation with serum creatinine. In a very recent paper, D’Anna et al. [13] reported that NGAL serum concentrations in the pre-eclampsia group were higher than in the control group, with significant differences in each trimester. They studied only 30 females in each group, and did not study in detail kidney function and other parameters.

The strength of our study is simultaneous measurement of serum NGAL and cystatin C. However, there are also some limitations. This is a single-centre, cross-sectional study, without measurement of GFR. It was not possible to study true GFR using either isotopic methods or insulin clearance; therefore we estimated GFR from known formulae. Similarly to cystatin C, although reference ranges have been reported, there is no current standard for serum NGAL measurements. In addition, testing for NGAL is only available in a limited number of laboratories using ELISA assay. However, urinary and plasma assay enabling more rapid measurement are under development.

In conclusion, serum NGAL in pregnancy might reflect subclinical inflammation rather than kidney function. It seems that NGAL, similarly to cystatin C, is not useful to monitor renal function in pregnancy.

\section{References}

1. Davison JM, Dunlop W. Renal haemodynamics and tubular function in normal human pregnancy. Kidney Int 1980; 18: 152-61.

2. Deinum J, Derkx FH. Cystatin for estimation of glomerular filtration rate? Lancet 2000; 356: 1624-25.

3. Malyszko J, Bachorzewska-Gajewska H, Sitniewska E, Malyszko JS, Poniatowski B, Dobrzycki S. Serum neutrophil gelatinase-associated lipocalin as a marker of renal function in non-diabetic patients with stage 2-4 chronic kidney disease. Ren Fail 2008; 30: 625-8.

4. Levey AS, Stevens LA, Schmid CH, et al; CKD-EPI (Chronic Kidney Disease Epidemiology Collaboration). A new equation to estimate glomerular filtration rate. Ann Intern Med 2009; 150: 604-12.

5. Hoek FJ, Kemperman FA, Krediet RT. A comparison between cystatin C, plasma creatinine and the Cockcroft and Gault formula for the estimation of glomerular filtration rate. Nephrol Dial Transplant 2003; 18: 2024-31.

6. Manetti L, Pardini E, Genovesi M, et al. Thyroid function differently affects serum cystatin $C$ and creatinine concentrations. J Endocrinol Invest 2005; 28: 346-9.
7. Strevens H, Wide-Swensson D, Grubb A, et al. Serum cystatin $C$ reflects glomerular endotheliosis in normal, hypertensive and pre-eclamptic pregnancies. BJOG 2003; 110: $825-30$

8. Strevens $H$, Wide-Swensson D, Hansen A, et al. Glomerular endotheliosis in normal pregnancy and preeclampsia. BJOG 2003; 110: 831-6.

9. Kristensen K, Larsson I, Hansson SR. Increased cystatin C expression in the pre-eclamptic placenta. Mol Hum Reprod 2007; 13: 49-55.

10. Costantini S, Di Capua E, Zerega B, et al. Pilot study on lipocalin expression into extracellular fluids of women in fertile age. Minerva Ginecol 2002; 54: 387-92.

11. Lavery AP, Meinzen-Derr JK, Anderson E, et al. Urinary NGAL in premature infants. Pediatr Res 2008; 64: 423-8.

12. D'Anna R, Baviera G, Giordano D, et al. Neutrophil gelatinase-associated lipocalin serum evaluation through normal pregnancy and in pregnancies complicated by preeclampsia. Acta Obstet Gynecol Scand 2010; 89: 275-8. 